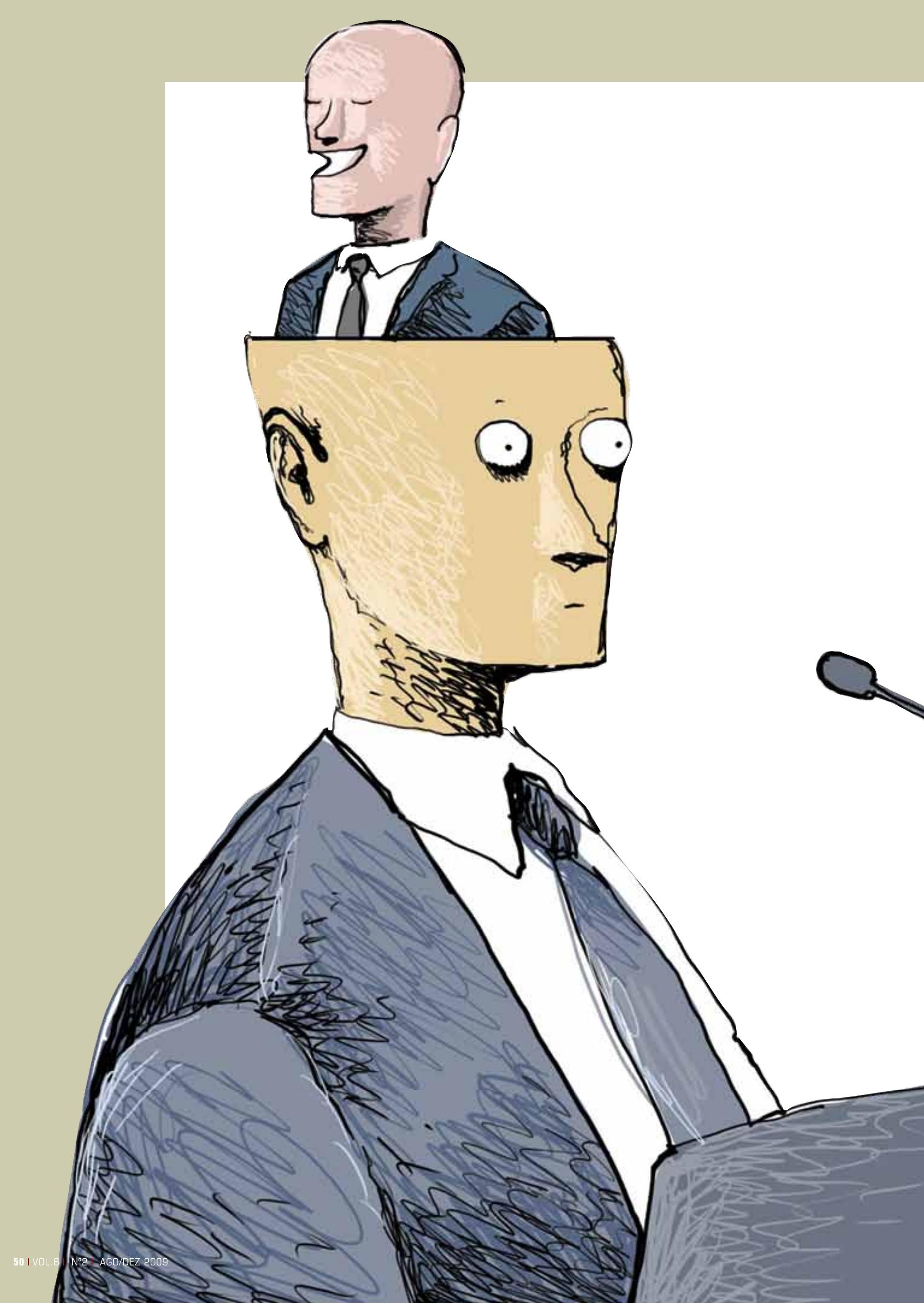




\section{OS DOIS LADOS DO MEDO}

\section{0 medo é um sentimento inerente à vida das organizações.}

\section{Mas, se de um lado ele traz incontáveis prejuízos às pesso-}

\section{as, também pode protegê-las de exposições destrutivas,}

\section{além de estimular o autoconhecimento}

\section{POR SYLVIA CONSTANT VERGARA}

Emilio Mira y López, psicólogo espanhol, dizia que nossa alma tem quatro gigantes: medo, ira, dever e amor. Os três primeiros colocam obstáculos em nossa vida, enquanto o último abre portas. Este artigo destaca o primeiro, conceituando-o, apresentando as situações que o desencadeiam, os efeitos que causa, as estratégias defensivas que provoca e as possibilidades que abre.

O QUE É MEDO? Medo é uma emoção inerente à nossa vida. É possível que tenhamos medo de adoecer, de estar vulneráveis a um cataclismo natural, de caminhar à noite pelas ruas da cidade, enfim, é possivel que, a partir de nossos referenciais, tenhamos medo de muitas situações e agentes diferenciados.

Zygmunt Bauman, sociólogo polonês, nomeou nossa era contemporânea de modernidade líquida. Ela é caracterizada pela agitação, fragmentação, ambivalência, pelo incompreensível e pela contingência. Medo, nessa modernidade, é a incerteza, definida como nossa ignorância da ameaça e do que pode ou não ser feito para fazê-la cessar.

O medo pode valer-se de máscaras como a timidez, o pessimismo, a arrogância, o tédio, a vaidade, a hipocrisia e a mentira. Existem medos patológicos, como a fobia e o pânico.

MEDO NAS ORGANIZAÇÕES. Nas organizações, podemos ter medo de uma situação concreta presente, do inesperado, do desconhecido. Mudanças organizacionais em estratégias e regras nas quais nos apoiamos nos colocam frente ao desconhecido e podem provocar-nos medo. Perderemos boas condições de 


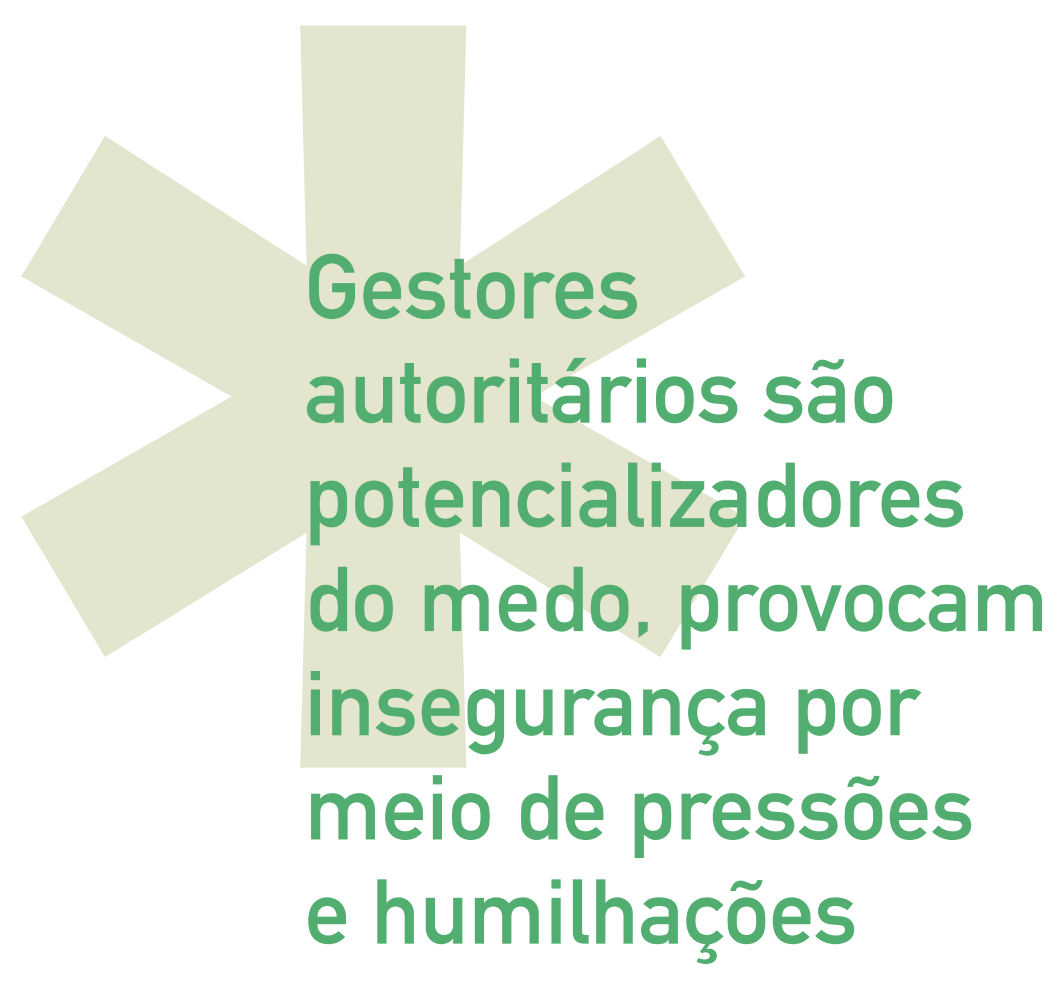

trabalho, status, poder, liberdade, contatos, alianças? Todos nós construímos nossa identidade nas relações que temos com nosso público de relacionamento e conosco; então, mudanças podem significar perda de identidade, e, com ela, vem o medo. Resistimos às mudanças porque nos sentimos ameaçados, tanto pela ausência de informações sobre o futuro quanto por considerarmos que talvez não nos seja possível dela dar conta.

Não é raro o medo de sermos punidos por quem nos chefia. Mesmo que isso nunca nos tenha antes acontecido, a ameaça, velada ou explícita, acaba por provocar temor. Do processo, nossa imaginação pode ser causadora e até potencializadora.

É bem possível que, se não soubermos realizar uma determinada tarefa ou se sobre ela tivermos dúvida, tenhamos receio de pedir ajuda e ser considerados incompetentes. Também podemos ter medo de um colega corajoso que "vá em frente" e, se houver comparação com nosso desempenho, acabe por abrir às portas à nossa demissão ou, no mínimo, à nossa mudança (indesejada) de setor. Para a organização, significa a impossibilidade de compartilhamento de conhecimento entre seus membros.

A não conformação à cultura organizacional pode provocar possibilidade de demissão, e, com ela, vem o medo e seus efeitos. Como podemos nos sentir pertencendo a uma equipe sem ter a certeza de estarmos empregados na próxima semana? O medo de sermos demitidos pode ser potencializado pelo receio do que irá nos acontecer depois da demissão. Conseguiremos um novo emprego? Que segurança temos?

EFEITOS DO MEDO. Com o medo podem vir a ansiedade, o estresse, a queda da produtividade, o travamento. A ansiedade é um composto de medo e antecipação de situações. Construímos mentalmente uma realidade e lançamos mão de defesas psicológicas que acabam por gerar estresse, com perdas para os resultados organizacionais.

Gestão por meio de intimidação, de exigências absurdas, de ameaças sistemáticas, tende a nos paralisar porque nos quebra a autoestima. Se nos sentimos como menos, como é que vamos produzir como mais? Gestores autoritários são potencializadores do medo. Ao contrário de um líder que provoca segurança e obtém os resultados esperados pela capacidade de estimular sua equipe, um gestor autoritário provoca insegurança por meio de pressões e humilhações. Quando isso ocorre, para não comprometermos nossa carreira, decidimos colaborar.

O medo pode ser potencializado por pressões externas e energias internas, ou, ao contrário, pode ser mitigado quando há um processo de adaptação, ocasionado, por exemplo, pela repeti- 
ção do que provocou tal processo. Em uma organização, o medo que foi desencadeado em um indivíduo pode provocar um medo coletivo. Michel Foucault, filósofo francês, diz no livro História da Loucura, no qual trata de sentimentos perniciosos: "[...] o mal entra em fermentação nos espaços fechados [...] entra em ebulição, soltando vapores nocivos e líquidos corrosivos [...] Esses vapores ferventes elevam-se a seguir, espalham-se pelo ar e acabam por cair nas vizinhanças, impregnando os corpos e contaminando as almas".

Em culturas organizacionais repressivas deixamos de atuar de acordo com o que sabemos, de criar, de inovar. Coisas simples, como revelar que uma determinada decisão gerencial não está dando certo, que os clientes estão reclamando disso ou daquilo, deixam de ser feitas. Silenciamos, não ousando apresentar outro modo de ver a realidade. De nós espera-se que mantenhamos a boca fechada e nos submetamos às regras impostas. Ou deixemos a organização. E como nos defendermos do medo?

ESTRATÉGIAS DEFENSIVAS. Para evitarmos ou nos livrarmos do medo e dos efeitos dele decorrentes, desenvolvemos o que Ana Freud chamou de mecanismos de defesa. Por exemplo, a fuga - que pode ser tanto passiva quanto ativa. A fuga passiva é a repressão da vontade de realizar algo. É, como diz Myra y López, uma fuga profilática. Seu tempero é a prudência. Fazemos tudo o que podemos para passarmos despercebidos. A inércia é nossa defesa. Já a fuga ativa é a defesa ante uma situação. É o caso, por exemplo, de não desejarmos qualquer alteração em nossas tarefas e, no entanto, se a ela somos obrigados, mudamos nosso comportamento.
É bem possível que o medo nos leve a atribuir problemas gerados em um departamento a outro grupo de pessoas ou a uma só pessoa. É o "bode expiatório", sobre o qual recaem todas as culpas por algo não ter dado certo.

Talvez sejamos criativos, inovadores em nossa tarefa, redundando em aumento da produtividade. Com ela, levamos vantagem em relação a colegas, afastando o medo de sermos desligados da organização. O temor de que algo indesejável ocorra pode provocar coragem para a realização do que não nos considerávamos aptos a realizar.

DO INIMIGO AO ALIADO. Ora, se de um lado o medo traz todos os efeitos indesejáveis apontados neste artigo, de outro também possui funções positivas. Ele pode ser, por exemplo, um aliado à nossa própria preservação, além de nos permitir condições para nosso autoconhecimento. De fato, sem o medo nos lançaríamos diretamente ao perigo. Ele nos torna mais atentos ao que ocorre ao redor. Ele não nos permite transgredir a linha entre o possível e o impossível.

Mas devemos tentar identificar as máscaras de nosso medo, saber o que tememos e por que isso nos torna vulneráveis. $O$ medo pode sinalizar o que para nós representa uma ameaça; daí, a necessidade de tomarmos consciência dessa representação, suas causas e suas saídas. Ele nos enseja desenvolver competência para avaliar sua periculosidade, desconstruir as grades psicológicas que o sustentam e acionar ações que restrinjam sua força destrutiva. Ganhamos nós e a organização. A energia gasta em estratégias defensivas pode ser canalizada para outras que ajudem a organização a crescer. 